conducted by USDA disclosed frequent instances of fraudulent record keeping. Frankie Trull, president of the National Association for Biomedical Research, says, "We'd like to see the USDA enforce the 'regs' already on the books and get the bad dealers out of the business."

But pet protection advocates feel the proposed new legislation is necessary. "The class B dealer system has created an incentive for dealers to steal animals instead of getting them by legitimate means," claims Tony Swanick, spokesperson for Rep. Fox. In addition to eliminating $\mathrm{B}$ dealers, both Fox's bill and Canady's bill would let the states decide whether animal pounds could sell directly to research facilities.

If either bill is ultimately approved, researchers like Galante will be hard-pressed to find new dog sources. The same animal rights agenda that has rallied support for the new pet protection bills has already succeeded in lobbying fourteen states to prohibit pounds and shelters from selling animals to research facilities. "Specific new breeding colonies would have to be established to provide adequate numbers for our use and that of other investigators around the country," says Galante. Establishing such breeding colonies would likely take several years and increase the cost for one dog from hundreds to thousands of dollars.

BARBARA NASTO New York, New York

\section{Science not wasted on the young}

The 390 enthusiastic summer students who presented their research at the sixth annual US National Institutes of Health Poster Day represent an encouraging level of interest in science among young people. Under the leadership of the Office of Education and its director, Michael Fordis, the NIH Summer Internship Program in Biomedical Research has rapidly expanded in the last several years.

One thousand participants, predominantly high school or college students hailing from all parts of the USA and even from as far away as Guam and Japan, enrolled in this year's program. Students spent 8-10 weeks from June to August in research laboratories scattered throughout the NIH's 17 institutes, concluding their stay with the hugely popular poster day.

Although they had only a relatively short time in the laboratory, confident participants presented scientific posters detailing a wide spectrum of research from clinically orientated data analysis to basic molecular biology. "The limitations are not so much technical anymore as they are intellectual," said Michael Gottesman, director of intramural research for NIH. "Molecular biology projects can be summer projects."

\section{DID YOU KNOW?}

Few Cornell medical students take "extraordinary opportunity"

Does a free year of medical school following a year of living in New York for only $\$ 400$ a month sound too good to be true? Each of the 119 students accepted to Cornell University Medical College for the 1996-1997 school year received such an offer in the form of a letter from Gordon Fairclough, Ir., chairman of the admissions committee, who called it an "extraordinary opportunity." The only cost to the student is to wait a year before beginning medical school. However, only five students accepted the offer, and another "five or six are considering it," according to assistant dean of admissions Mary Lou Handy. A higher-than-expected number of acceptances from students offered a place in the class led to the generous - and surprisingly spurned - offer.

Fintan R. SteEle. cent biology graduate of the University of Maryland, says that her four summers at the NIH have steered her toward a career in medically oriented research. About to start the George Washington University/NIH graduate program in genetics, Kulansky is enthusiastic about her career choice and is looking forward to continuing her research as a full-time member of the NIH community.

Program participants not only gain valuable experience in top research laboratories, but also have the opportunity to attend a special seminar series featuring distinguished speakers from the NIH and a one-day career workshop. The NIH's internship program has certainly generated diversity in career choices. Soon to depart for the University of Pennsylvania, Seth Ginns is planning to major in physics and then to apply to medical school. Fellow high school graduate, Ann-Robin Anthony, in her third summer working in the Laboratory of Cardiac Energetics at the National Heart, Lung and Blood Institute, says that her experience at the NIH prompted her decision to pursue biomedical engineering at Duke University. Now concluding her fourth summer at the NIH, Marian Lee is studying history and government at Harvard. Although the decision to study humanities rather than biological sciences proved difficult, Lee points out that her research experience will be an invaluable asset when she pursues a doctorate in public health.

The success of the NIH summer research program was perhaps best summed up by Gottesman, who remarked on poster day that "you can feel the electricity here: the students love it and the faculty love it."

OrLa SMITH 